Prof Sandiso Ngcobo

Mangosuthu University of

Technology

sandiso@mut.ac.za

Dr Makhulu Makumane

National University of Lesotho

Makhulum@yahoo.co.uk

DOI: $h t t p: / / d x . d o i$.

org/10.18820/2519593X/pie.

v37i1.5

ISSN 0258-2236

e-ISSN 2519-593X

Perspectives in Education

2019 37(1): 58-71

Date Published: February 2020

\section{Pre-service teachers' attitudes toward the teaching of Mandarin in South Africa}

\begin{abstract}
The Constitution for the Republic of South Africa (Act 108 of 1996) embraces language as a basic human right and multilingualism as a national resource. One latest foreign language to be given recognition by the Department of Basic Education (DBE) in 2015 is Mandarin, a Chinese language, for incremental implementation as a non-official optional language from 2016 in primary schools. One of the stakeholders at the centre of the implementation of this latest foreign language to be recognised, whose voice has not been heard, are teachers. The methodology adapted in the collection of data is quantitative in that pre-service teachers completed a questionnaire. The results indicate mixed attitudes with more appearing to be not entirely supportive of this move by the DBE. Teachers do not share the same sentiments that are expressed at political level about the significance of Mandarin for trade and globalisation. The findings suggest a need for the DBE to rethink this plan and training proportional to the minimum training requirements for the teaching of a foreign language to be provided to teachers. There would need to be some consultation to ensure a greater teachers' support as the project continues to be piloted and implemented in more schools across the country.
\end{abstract}

Keywords: Mandarin, teachers, attitudes, globalisation, indigenous languages

\section{Introduction}

South Africa (SA) is multilingual with eleven official languages that are recognised by its democratic Constitution. In this regard, the Constitution for the Republic of South Africa (Act 108 of 1996) embraces language as a basic human right and multilingualism as a national resource in that citizens are encouraged to learn one another's languages. Moreover, the Constitution promotes multilingualism through the development of languages that are foreign to the country, such as, Arabic, German, Greek, Hebrew, Hindi, Portuguese and Tamil. The latest foreign language that has been introduced by the South African office of the Minister of the Department of Basic Education (DBE), Angie Motshekga, is a Chinese language called Mandarin. This directive was issued through Circular S10 of 2015 on incremental implementation of Mandarin as a nonofficial optional language from 2016-2018. The teaching of Mandarin in SA was justified by the DBE as necessary for 
trading reasons with China. There was also mention of China being committed to providing materials, sending volunteers and training SA teachers.

The decision on its own has some merits in light of the fact that many other countries that have economic ties with China also teach Mandarin. News24 (2015) suggests that South Africa could be a late comer as Mandarin has long been taught in other southern African countries. Markell and Herbert (2016) note a similar trend in the United States of America where, after Spanish, Mandarin was the most popular dual-language education programme implemented by individual states in 2013. Paton (2014) is also in support of Mandarin in the United Kingdom and Malley (2016) in Australia. Wang (2013: 25) views this global interest in Chinese as due to its growing importance for trade, diplomacy, cultural exchange and better jobs. Other benefits associated with being multilingual due to learning a foreign language that could be relevant for SA learners are academic achievement, cognitive development, critical thinking and multiculturalism (Burton, 2018; Chikiwa \& Schäfer, 2018; Kormos \& Kiddle, 2013). Citing Lo Bianco (2007: 6), Wang (2013) asserts that the popularity of Chinese could soon cause it to be regarded as the "new English".

Despite this global interest and value of Mandarin, it has become controversial in SA because of different views held by educational stakeholders. One of the stakeholders to challenge this circular was the South African Democratic Teachers Union's (SADTU), which labelled the announcement as the "worst form of imperialism". SADTU's concern is worthy of attention because it is the largest teacher's union in SA with approximately 254000 members and it is aligned to the ruling party, the African National Congress (ANC). In response, the Department of Basic Education (DBE) claimed that the decision was influenced by a growing demand for Mandarin by parents (Nkosi, 2015). However, the DBE did not present any figures or consultation proof to substantiate its claim that the decision was based on parents' demand. Moreover, the DBE is not the mouthpiece of the parents, unlike SADTU, which could argue that it represents the teachers' voice. It is, however, problematic that SADTU also did not explain the process through which it consulted teachers on this particular issue. There is therefore a need to conduct a study on what are the teachers' attitudes on the teaching of Mandarin in SA. Moreover, in the South African context, language is a very emotive issue that has previously resulted in the death of many youths and destruction of property. On 16 June 1976, African youths of Soweto came out to the streets to resist a language that was not theirs which was imposed on them by the then illegitimate government. It was through the Bantu Education Department that the government gave the directive that Afrikaans was to be used by Africans as one of the languages of instruction at secondary school level. The Soweto youths' confrontation with the police spread to many parts of South Africa and resulted in the death of many people (https://www.sahistory.org.za/topic/june-16-soweto-youth-uprising). The language issue remains emotive judging by the fact that it also came up in the recent (2015-2017) \#FeesMustFall university students' revolts which were also characterised by confrontations with the police and destruction of property. Students, academics and various stakeholders raised the language of instruction issue as essential towards decolonising education. A demand continues to be made for African languages to be used alongside English and Afrikaans for knowledge production and equitable access to knowledge (Mdube, 2018; Mheta, Lungu \& Govender, 2018; Writer, 2019)

Closer to China, in Hong Kong, where Mandarin is one of the three official languages, it has also become controversial. According to media reports, some students who perceive it as the language of the enemy, which is mainland China, are rejecting it. Lo (2018), however, 
argues that this students' rejection of Mandarin goes beyond language but touches on matters of identity in Hong Kong. In January 2018, Hong Kong Baptist University students are reported to have embarked on a protest march in opposition to the mandatory Mandarin test to qualify for graduation. Amongst other concerns was that the test was too difficult to pass after $70 \%$ of the candidates had failed it (Chiu, 2018). This was not the first instance in which students had demonstrated dissatisfaction with Mandarin. Mair (2018) reports that the 2016 students' referendum indicated that nearly $90 \%$ of the 1544 participants rejected the university policy requiring them to either enrol in a Mandarin course or prove their language proficiency.

Therefore, on the Mandarin issue in South Africa, teachers' views are equally significant to interrogate because teachers are expected to undergo training in China so that they can implement this policy in their schools. Merrington (2016) reports that the Basic Education Minister, Angie Motshekga, told parliament that in 2016 there were 43 schools that had introduced Mandarin in SA. This number falls short of the DBE vision to introduce Mandarin in 500 schools over the next five years across the country. Moreover, out of nine provinces, this has, however, happened in only four provinces. Even then, the distribution is not balanced because 11 of these schools are in Gauteng, 26 in the Western Cape; there are three in the Eastern Cape and three in KwaZulu-Natal. Against this ambitious plan, Writer (2016) and Merrington (2016) note that the Minister of Basic Education conceded in parliament that they were at that moment relying on teachers sent from China. The bigger plan was to provide a three-week training of 100 SA teachers who will be sent to China every year. Yet, experts were cited in the media report as indicating that learning to teach Mandarin as a foreign language can be a very daunting task requiring up to five to six years of full-time training. In light of this and many other concerns, opposition political parties are reported to have called for delays in this project until proper consultation had taken place with stakeholders in the education sector. Teachers, as already noted, are critical stakeholders in this project. This therefore points to the need to investigate if they would be willing to not only implement the project but also support it by, amongst other things, undergoing the initial challenging training that they would require.

Along the same line of concern, Jansen (2001) cautions against assumed policy images of teachers that may be in conflict with their actual personal identities as practitioners. This conflict, if not well managed, may lead to implementation dilemma in educational reform. Jansen (2001) argues that this type of concern presents a new line of research inquiry that has long been neglected in education. Nel (2016: 44) is of the same view when asserting that prior to the Chinese project being widely piloted and implemented in SA, there is a need for immediate (and ongoing) proactive research "to ensure that challenges are overcome before they become insurmountable".

Thus, the aim of this article is to explore attitudes of newly qualified language teachers on the teaching of Mandarin in South African schools. The attitudes of South African preservice teachers towards Mandarin are unknown whereas language is such an emotive issue in the country. The article aims to address this research gap that came to light with the recent controversial announcement that Mandarin is to be taught in many government schools in the near future. The question that guides the article is "what are teachers' attitudes towards the teaching of Mandarin in South African schools?" 


\section{Language attitudes}

The article is on teachers' attitudes towards the teaching of Mandarin in South African schools. For this reason, the term "attitude" is critical as a point of departure in the review of the literature as it constitutes the phenomenon of this study. This is more so because the concept is vaguely defined in the literature whereas in order to accurately study and measure attitudes the concept's definition must be precisely presented (Altmann, 2008: 144). In the presence of many and contradictory definitions, Altmann (2008) recommends a decision to choose the most useful in relation to the aims of the research inquiry. For instance, Dietz-Verrier (2015: 21) indicates that there are two different theoretical approaches that can be used to define attitudes. On the one hand, there is the mentalist theory that depicts attitudes as a "mental and neural state of readiness" which makes them not to be "directly observable but have to be inferred from the subject's introspection" (citing Agheysi \& Fishman 1970:138). Dietz-Verrier (2015) finds this view problematic since it implies that the researcher has to rely on participants' reports pertaining to their attitudes "or infer attitudes directly from behaviour patterns" (citing Fasold 1984: 147). On the other hand, there is the behaviourist theory that defines attitudes as "responses people make to social situations" Dietz-Verrier (2015, citing Fasold 1984:147). Dietz-Verrier (2015: 21) describes the behaviourist theory as less problematic as it requires the researcher to simply observe, collect and analyse data. The only challenge raised is that the data collected in this manner fail to account for other behaviour (citing Agheysi \& Fishman 1970: 138; Fasold, 1984: 148).

Against these contradictory theories, the article adopts a definition by Oroujlou and Vahedi (2011: 997), citing Smith (1971) who describe an attitude as an enduring organisation of beliefs around an object or a situation. The learnt beliefs predispose one to react in some preferred manner that can be either positive or negative towards an object such as a foreign language. Moreover, attitudes do not occur in a vacuum but rather within a particular situation such as a social environment where a teacher is expected to learn and teach a foreign language. Attitudes in respect of a foreign language are important because they also influence a person's motivation or lack thereof to learn it (Dörnyei, 2001).

In the same vein, a teacher who views the teaching of a foreign language in a negative manner might not be willing to learn it so that they can be in a better position to implement the policy that requires one to do so. In cases where they do not have an option, they would not exert themselves in a manner that would be beneficial to them and their learners. BundgensKosten (2009: 21), however, clarifies that attitudes do not always require to be learnt over time because a person can react to an object "on the spot". The difference under such circumstances is that the attitude will have a very low attitude strength. It is equally expected in this article that the participants who are pre-service teachers might not have heard about this latest language development in the field of education that they would soon be joining. Yet, they will be expected to express their views on the spot.

In relation to the above definition and its explanation, Nel (2016: 55) reports on a South African pilot project in which the teaching of Mandarin received favourable responses from the learners. The learners attributed the success of the project to the Chinese teacher's friendly attitude, patience, support, her willingness to repeat things and efforts made to make the classes fun. She also went out of her way in her teaching by employing technological support such as in the form of tablets, laptops, big screen TVs and e-learning processes to facilitate her lessons in a manner that would appeal to learners. Nel (2016: 50, citing Rhodes 2014), associates the success of this teacher's lessons with the fact that she is highly qualified, 
something that is a priority in foreign language teaching. Yet, Nel argues, citing Halliday (2014), that the best teachers that have been found to be most effective in the teaching of Chinese were those who spoke the same language as the learners. In the same vein, Tan (2017: 18) asserts that trained teachers are much better language learning models because they would have also undergone the same experience of learning a language than those for whom it is their first language. In light of the South African government plans to extend the teaching of Mandarin to approximately 500 schools per year, it cannot rely on teachers from China. There is a need to train South African teachers that are however positive about the teaching of this foreign language because of the intensity that comes with the training and teaching.

A relevant model worth exploring is the socio-educational model to foreign language acquisition. Through this model, Masgoret and Gardner (2003:124) propose three components to foreign language learning. These are integrativeness, attitudes toward the learning situation and motivation. Integrativeness and attitudes toward the learning situation are described as "two correlated variables that support the individual's motivation" to learn a foreign language (ibid). First, integrativeness is explained to mean that the learning of a foreign language requires the adoption of language aspects that are part of the culture of that community. This can include the willingness to adopt the "word sounds, pronunciation, word orders and other behavioural features that are part of another culture" (126). However, Gardner (2005) clarifies that attitudes to integrativeness are dependent on how individuals feel about their own heritage. In cases where individuals value their ethno-linguistic heritage as part of their identity, such as their own language, they would be less willing to support integrativeness.

Second, for integrativeness to occur, one needs to have a favourable attitude toward the community that speaks the language. Attitudes toward the learning situation involve the individual's reaction to matters such as the textbooks, learning materials and the teaching environment of the foreign language. Third, motivation requires a "favourable attitudes toward the learning situation" with its available learning resources (128). In addition to the three components, Gardner (2012: 217) introduces the fourth variable, which is language anxiety. Anxiety has implications for success in learning a foreign language "as well as to attitudes toward the learning situation and possibly integrativeness" (Gardner, 2012: 217). The socioeducational model is relevant in the investigation of attitudes because of the difficulty that is associated with the learning of Mandarin. This difficulty is in part because Chinese migrant nationals tend to avoid integrating with local communities for security, economic and social identity reasons (Gukurume, 2019: 94).

Teagle and Chiu (2016) attribute the difficulty that comes with learning Mandarin as related to the amount of characters $(50000)$ instead of 23 alphabet letters as well as its tonal nature and familiarity with Chinese culture that one requires to be able to understand the language. They cite these factors as having contributed to the failure of Mandarin programmes in Australian schools. The other concern, raised by Teagle and Chiu (2016), is the fact that there will also be a need to train local teachers, through volunteers from China, who might also struggle to grasp this foreign language to be able to teach it effectively. Teagle and Chiu (2016: online) rather recommend a focus on "promoting cross-cultural understanding between South Africa's own peoples by teaching indigenous languages".

Another dimension brought forward about attitudes by Oroujlou and Vahedi (2011: 997) is that they are dynamic in that they can be learnt and unlearnt. This implies that attitudes do change over time as they can shift from being, for instance, negative to positive. One of the 
factors that contributes to attitude change among teachers is education. Byrnes et al. (1997) found that teachers who had received formal training that equipped them with the necessary skills and knowledge to teach effectively had positive language attitudes. This implies that the Mandarin teachers who will be recruited to undergo a three-week training course in China might find the time inadequate and come back lacking in confidence which could lead to negative attitudes. Similarly, the participants in this study might respond negatively if they learn that they would be expected to receive a mere three-week training on a language they have never used before in their lives. This is to be expected against the backdrop that the participants have trained for four years on the teaching of English second language (ESL) which is not their mother tongue but a familiar language in South Africa. These favourable factors about English do not, however, imply that ESL teachers always feel confident about teaching the language. Wessels, et al. (2017:443) present figures that indicate that not only pre-service teachers but also experienced teachers often feel negative about their ESL proficiency which impacts on their ability to teach effectively.

Raselimo and Mahao (2015) are of the premise that the attainment of the new curriculum will depend on how the different stakeholders involved in the development and enactment of the curriculum understand the policy in their particular contexts. One of the critical stakeholders that is expected to enact the curriculum is teachers. However, in doing so, they would need to have a clear understanding of the curriculum's vision. According to Khoza (2016), the quality of teaching and critical thinking can be bolstered by an in-depth comprehension of the curriculum's visions and goals. This therefore deems it essential that teachers' understanding(s) and attitudes of the vision are examined, as this article set out to do. In this light, the success of the curriculum on foreign language teaching in KwaZulu-Natal is dependent on teachers' understanding(s) of the curriculum and their attitudes to foreign language teaching. Along the above views, Nel (2016: 54) reports success with the pilot teaching of Mandarin in a Pretoria school in the Gauteng province, South Africa because of the manner in which the Gauteng Education Department approached the school to offer Mandarin by clearly explaining its purpose and providing the necessary support.

Baker (1988: 112-115) further notes that attitudes can be quite complex because they are not always simply positive or negative. There are instances where both positive and negative attitudes can be attached to a language. In this regard, Ngcobo (2013) uses the term "conflicting attitudes" in describing a similar complex situation. This is whereby the teachers who participated in the study on the role of their own language in education did not display a single set of attitudes. Their attitudes revealed a rather complex set of contradictory beliefs. On the one hand, they provided responses that showed that they supported the use of African languages in education. On the other hand, responses to other questions showed that they were not consistent in their beliefs. For example, the majority indicated support for the role of their languages in education. Yet, a high number also said they sent their children to private schools where African languages were not encouraged.

Research into attitudes towards languages often adopts attitudinal Likert scales in the form of survey questionnaires (Dörnyei, 2001; 2007; 2010). For instance, Sakuragi's (2006) investigation into the relationship between attitudes towards L2 and cross-cultural attitudes utilised five-point scales (strongly agree to strongly disagree). 


\section{Methodology}

The study adopted a survey questionnaire that was piloted and then utilised among postgraduate students who were already qualified teachers but with no teaching experience, except the limited exposure gained as part of their training. Piloting of the research tool helped address issues of validity and reliability since the researchers were able to identify areas of confusion in the manner in which questions were phrased. The questionnaires were administered and collected in class after securing permission through the assistance of the identified contact person. The contact person assisted with the survey distribution and delivery to the researchers. Dörnyei (2007: 90) recommends questionnaires as a convenient tool in the collection of data on attitudes or opinions of a group of people. This is because "questioning only a fraction of the particular population" is adequate in generalising about the attitudes and opinions of a large population (Dörnyei \& Csizér, 2012). One hundred and nine questionnaires were found to be usable. Yet, the challenge with surveys is that they are based on self-report data which might lack validity because of the tendency of respondents to simply tick answers that they think the researcher expects (Neuman, 2014).

The survey was conducted towards the end of the year, 2017, when students were about to write examinations. The participants were purposefully selected because of their specialisation in ESL teaching (Teddlie \& Yu, 2007). Ethical issues were observed whereby the participants were provided with a letter of consent, which amongst other things, stated that they were free to decide whether they wanted to participate in the survey. They were also assured of anonymity.

In analysing the data, the Statistical Package for the Social Sciences programme was employed and the descriptive and inferential statistical analysis applied in the reporting.

\section{Results and discussion}

Each question in the questionnaire that was distributed to respondents was analysed individually to ensure that accurate results were displayed. In light of the fact that the participants were newly qualified teachers in the teaching of languages, it was considered imperative to inquire if they felt ready to face the real world. To this effect, the first statement was: "My training experience on how to teach a foreign language has been adequate".

\begin{tabular}{|l|l|l|l|l|l|}
\hline \multicolumn{7}{|l|}{ Table 1: Training experience on foreign language } \\
\hline & & Frequency & Per cent & $\begin{array}{l}\text { Valid Per } \\
\text { cent }\end{array}$ & $\begin{array}{l}\text { Cumulative } \\
\text { Per cent }\end{array}$ \\
\hline Valid & 1 & 3 & 2.8 & 2.8 & 2.8 \\
\hline & 2 & 33 & 30.3 & 30.3 & 33.0 \\
\hline & 3 & 33 & 30.3 & 30.3 & 63.3 \\
\hline & 4 & 14 & 12.8 & 12.8 & 76.1 \\
\hline & 5 & 26 & 23.9 & 23.9 & 100.0 \\
\hline & Total & 109 & 100.0 & 100.0 & \\
\hline
\end{tabular}


Data presented in Table 1 show that a low $2.8 \%$ of respondents strongly agreed, $30.3 \%$ agreed, another $30.3 \%$ were not sure, $12.8 \%$ strongly disagreed and $23.9 \%$ disagreed. These findings suggest that more than half of the respondents $(67 \%)$ did not feel adequately trained to undertake the task of teaching a foreign language. The findings are consistent with those made by Wessels et al. (2017) about foreign language teachers' negative feelings about their teaching proficiency. This is a cause for concern as Modipane and Themane (2014) aver that teachers are instrumental agents in a successful implementation of any curriculum. Therefore, if they (teachers) do not feel fit, so to speak, to teach a foreign language and have negative attitude towards it, this evidently puts effective implementation of a curriculum in jeopardy as teachers are probable to be disconnected from it due to a lack of motivation (Dornyei, 2001). This insinuation is supported by the reaction of respondents to the question of whether their training experience would influence the way they learn and ultimately teach any foreign language. In response, 9.2\% respondents strongly agreed, $44 \%$ agreed, $27.5 \%$ were not sure, $9.2 \%$ strongly disagreed and $10.1 \%$ disagreed. These results depict that $53.2 \%$ of respondents were of the opinion that their training would most likely have an impact on their practice. This suggests that pre-service teachers' attitudes towards a subject, in this instance a foreign language, are largely influenced by their training experiences. Thus, as Byrnes et al. (1997) predicate, equipping teachers with adequate and relevant skills and knowledge is liable to lead to effective learning, which might resultantly have a positive impact on their attitudes, and ultimately, their teaching.

In addressing the question of whether they would need more than three months to be able to teach Mandarin, intriguing results were seen. The results indicate that $27.5 \%$ of respondents strongly agreed, $22 \%$ agreed, $30.3 \%$ were not sure, $15.6 \%$ strongly disagreed and $4.6 \%$ disagreed. The fact that $49.5 \%$ agreed in varying degrees and $30.3 \%$ of respondents were not sure (which constitutes $79.8 \%$ ) talks to the need for the DBE to revise its plan and propose a programme that convincingly adheres to the minimal training requirements for teachers to be recognised as qualified to teach a foreign language (Council of Europe, 2001). In addition, respondents were equally unconvinced of their ability to learn and teach Mandarin, and this could also be attributed to the amount of time proposed for them to learn the language (see Table 2).

Table 2: Capability to learn and teach Mandarin

\begin{tabular}{|l|l|l|l|l|l|}
\hline & & Frequency & Per cent & Valid Per cent & $\begin{array}{c}\text { Cumulative Per } \\
\text { cent }\end{array}$ \\
\hline Valid & 1 & 7 & 6.4 & 6.4 & 6.4 \\
\hline & 2 & 28 & 25.7 & 25.7 & 32.1 \\
\hline & 3 & 49 & 45.0 & 45.0 & 77.1 \\
\hline & 4 & 13 & 11.9 & 11.9 & 89.0 \\
\hline & 5 & 12 & 11.0 & 11.0 & 100.0 \\
\hline & Total & 109 & 100.0 & 100.0 & \\
\hline
\end{tabular}


In reacting to the statement "I believe I am capable to learn Mandarin", Table 2 indicates that only $6.4 \%$ respondents strongly agreed, $25.7 \%$ agreed, $45 \%$ were not sure, $11.9 \%$ strongly disagreed and $11 \%$ disagreed. These results suggest that respondents were sceptical with their ability to teach Mandarin because of its foreign status, its limited access and scarcity and their unfamiliarity with its associated culture (Teagle \& Chiu, 2016). Moreover, the respondents display anxiety and negative attitudes toward the anticipated learning situation (Gardner, 2012).

Interestingly, respondents displayed even more cynicism with the successful implementation of Mandarin in the South African context. The reasoning was largely reliant on the capacity, financial muscle to see the implementation through and the limited space in the existing curriculum for such a scarce language. Statistically, results showed that $22.9 \%$ of respondents strongly agreed that it might not be feasible to teach Mandarin effectively in SA. Thirty-three point nine per cent agreed, $26.6 \%$ were not sure, $6.4 \%$ strongly disagreed and $10.1 \%$ disagreed. The implication of these results, especially when strongly agree, agree and not sure are merged, is that a large number of respondents, probably fuelled by their lack of understanding regarding the rationale behind the introduction of Mandarin and a negative attitude towards the utility and benefit of Mandarin in the South African context. According to Carl (2005), this attitude is liable to change if teachers are involved in policy development, as they would have deeper understanding of the vision. This is supported by Berkvens et al. (2014), who further insist on the essentiality of understanding policy/curriculum vision to favour positive attitudes towards teaching and critical thinking. This therefore suggests that teachers should be encompassed in policy and curriculum development in view of expanding the roles and responsibilities of teachers to help them be change agents in education (Samuel, 2008).

More than half of the participants responded favourably to the notion that the government should rather consider teaching other foreign languages that are easily accessible, most in Africa, such as French or Portuguese, instead of Mandarin. This was evident in that $22.0 \%$ of the respondents strongly agreed with this attestation, $31.2 \%$ agreed, $20.2 \%$ were not sure, $9.2 \%$ strongly disagreed and $17.4 \%$ disagreed. Alternatively, respondents seemed to support vividly an opinion that the government should rather encourage the teaching of indigenous SA languages such as Sesotho in KZN schools instead of opting for foreign languages. As in Table 3 below, an astounding $45 \%$ of respondents strongly agreed with this statement, while $36.7 \%$ agreed, $8.3 \%$ were not sure, with $5.5 \%$ and $4.6 \%$ strongly disagreeing and disagreeing respectively. These results seem to echo Teagle and Chiu's (2016) recommendation that the government should rather promote inter-culture, and to some extent multilingualism, by teaching indigenous languages to the locals. In addition, these findings further indicate a negative attitude towards foreign languages by teachers, which would obviously have implications on its implementation. This correlates with the caution provided by Gardner (2005) to the effect that favourable attitudes to their own language contributes to less willingness to support integrativeness. Previous studies conducted in South Africa among Africans show positive attitudes towards indigenous African languages by members of society at different levels (Mashiyi, 2014; Ndimande-Hlongwa \& Ndebele, 2017; Ngcobo, 2013; Sebolai 2017). 
Table 3: The government should encourage indigenous languages

\begin{tabular}{|l|l|l|l|l|l|}
\hline & & Frequency & Per cent & \multicolumn{1}{|c|}{$\begin{array}{c}\text { Valid Per } \\
\text { cent }\end{array}$} & $\begin{array}{c}\text { Cumulative } \\
\text { Per cent }\end{array}$ \\
\hline Valid & 1 & 49 & 45.0 & 45.0 & 45.0 \\
\hline & 2 & 40 & 36.7 & 36.7 & 81.7 \\
\hline & 3 & 9 & 8.3 & 8.3 & 89.9 \\
\hline & 4 & 6 & 5.5 & 5.5 & 95.4 \\
\hline & 5 & 5 & 4.6 & 4.6 & 100.0 \\
\hline & Total & 109 & 100.0 & 100.0 & \\
\hline
\end{tabular}

Makumane (2009) is of a premise that teaching/learning a foreign language includes exposure to the target culture. This is supported by Council of Europe (2001), which insists on teachers having adequate knowledge and competencies of both language and culture to be in a position to teach a foreign language. The findings of this study suggest that respondents subscribe to this belief, as $38.5 \%$ of them strongly agree that learning a foreign language requires a good understanding and exposure to its culture. Additionally, $44.0 \%$ agreed, $12.8 \%$ were not sure, $3.7 \%$ strongly disagree while $9 \%$ disagreed. These results suggest that for teachers to be in a position to teach Mandarin effectively, they would have to be exposed not only to the language but also to the culture that is embedded in the language. Thus, a plan to send South African teachers to China to learn Mandarin with the eventuality of teaching it seems to be a step in the right direction, as they would be directly exposed to both the language and the culture in real life situations rather than solely in a secluded formal setting.

\section{Conclusion}

The overall results of this study seem to suggest that pre-service teachers display negative attitudes towards the introduction of Mandarin in SA. A popular opinion among respondents was that Mandarin is "too foreign" as it is not a common language in the South African context, therefore it would be difficult to teach it. In addition, respondents seemed to prefer other foreign languages that were spatially accessible, such as French and Portuguese, over Mandarin, and even went further to indicate that they would prefer indigenous languages to foreign languages. Looming hindrances that appear to be influencing such negative attitudes from student teachers are the proposed timeline for training (three months), their belief and motivation, or lack thereof in teaching the language, and the accessibility of the target culture. Moreover, teachers do not seem to understand the rationale behind the introduction of Mandarin when there are indigenous languages that can be introduced in provinces where such languages are nearly non-existent, for instance, Sesotho in KZN. A possible solution to change teachers' attitudes from negative to positive towards the introduction of Mandarin is to involve them in the planning stages of this seemingly advantageous initiative. The advantages of their active involvement would influence deeper understanding of the rationale in learning a foreign language and becoming multilingual, which are mainly for academic achievement, critical thinking, cognitive development, trade and globalisation purposes. Lastly, the DBE needs to revise its plan by proposing a lengthier amount of time for the training of teachers in order for them to meet the minimum requirements for the teaching of a foreign language. 


\section{References}

All Africa Global Media. 2016. Introduction of Mandarin at local schools important - Authorities. News report, 27 August 2015.

Berkvens, J., Van den Akker, J. \& Brugman, M. 2014. Addressing the quality challenge: Reflections on the post-2015 UNESCO education agenda. England: Netherlands National Commission for UNESCO.

Bundgens-Kosten, J. 2009. Teachers' attitudes toward African American Vernacular English: Influence of contact with linguistics on ambivalent attitudes. PhD thesis. Frankfurt am Main: Goethe-Universität.

Burton, N. 2018. Beyond words: The benefits of being bilingual. Available at https://www. psychologytoday.com/us/blog/hide-and-seek/201807/beyond-words-the-benefits-being-bilingual

Byrnes, D.A., Kiger, G. \& Manning, M.L. 1997. Teachers' attitudes about language diversity. Teaching and Teacher Education, 13(6), 637-644. https://doi.org/10.1016/ S0742-051X(97)80006-6

Carl, A. 2005. The "voice of the teacher" in curriculum development: A voice crying in the wilderness? South African Journal of Education, 25(4), 223-228.

Chan, W.M., Chin, K.N., Bhatt, S.K. \& Walker, I. 2012. Individual characteristics and foreign language education: An introduction to the book. In W.M. Chan, K.N. Chin, S.K. Bhatt \& I. Walker (Eds.). Perspectives on individual characteristics and foreign language education (pp. 1-26). Berlin: Mouton de Gruyter. Doi: https://doi.org/10.1515/9781614510932.27

Chikiwa, C. \& Schäfer, M. 2018. Promoting critical thinking in multilingual mathematics classes through questioning. EURASIA Journal of Mathematics, Science and Technology Education, 14(8), 1-15. DOI: https://doi.org/10.29333/ejmste/91832

Chiu, P. 2018. Hundreds march on Hong Kong University to decry mandarin row suspensions. Available at http://www.scmp.com/news/hong-kong/education/article/2130774/ hundereds-march-hong-kong-university-decry-mandarin-row

Council of Europe. 2001. Common European framework of reference for languages: Learning, teaching, assessment. Strasbourg: Cambridge University Press.

Dietz-Verrier, C. 2015. Language attitudes in Hawick: An empirical study. Hamburg: Anchor.

Dörnyei, Z. 2001. Teaching and researching motivation. Harlow: Pearson Education.

Dörnyei, Z. 2007. Research methods in applied linguistics: Quantitative, qualitative, and mixed methodologies. Oxford: University Press.

Dörnyei, Z. 2010. Questionnaires in second language research: Construction, administration, and processing (2nd ed.). London: Routledge. https://doi.org/10.4324/9780203864739

Dörnyei, Z. \& Csizér, K. 2012. How to design and analyze surveys in SLA research? In A. Mackey \& S. Gass (Eds.). Research methods in second language acquisition: A practical guide (pp. 74-94). Malden, MA: Wiley-Blackwell. https://doi.org/10.1002/9781444347340.ch5

Gardner, R.C. 2005. Integrative motivation and second language acquisition. A joint plenary address presented at the meetings of the Canadian Association of Applied Linguistics and the Canadian Linguistics Association on May 30, 2005 at The University of Western Ontario: Canada. https://doi.org/10.14746/ssllt.2012.2.2.5 
Gardner, R.C. 2012. Integrative motivation and global language (English) acquisition in Poland. Studies in Second Language Learning and Teaching, 2(2), 215-226.

Gukurume, S. 2019. Chinese migrants and the politics of everyday life in Zimbabwe. Asian Ethnicity, 20(1), 85-102 https://doi.org/10.1080/14631369.2018.1490174

Jansen, J.D. 2001. Image-ining teachers: Policy images and teacher identity in South African classrooms. South African Journal of Education, 21(4), 242-246.

Kormos, J. \& Kiddle, T. 2013. The role of socio-economic factors in motivation to learn English as a foreign language: The case of Chile. System, 41, 399-412. https://doi.org/10.1016/j. system.2013.03.006

Lo, A. 2018. Hong Kong students the real losers in language battle. Available at http://www.scmp.com/comment/insight-opinion/article/2130639/ hong-kong-students-real-losers-language-battle

Makumane, M. 2009. Elaboration d'un curriculum pour la reintroduction du français langue étrangere au Lesotho. Master's dissertation. Cape Town, South Africa: University of Cape Town.

Masgoret, A.M. \& Gardner, R.C. 2003. Attitudes, motivation, and second language learning: A meta-analysis of studies conducted by Gardner and Associates. Language Learning, 53(1), 123-163. https://doi.org/10.1111/1467-9922.00212

Mair, V. 2018. Forcing Mandarin on Hong Kong. Available at http://languagelog.ldc.upenn. educ/nll/?p=36381

Markell, J. \& Herbert, G.R. 2016. Mandarin learning is a must: Learning Mandarin is critical to the educational and economic success of American students. Available at https://www.usnews.com/opinion/knowledge-bank/articles/2016-10-25/ teaching-mandarin-chinese-should-be-a-priority-for-american-schools

Malley, A. 2016. Why learning Chinese should be compulsory in Australian schools. http:// www.smh.com.au/business/workplace-relations/chinese-language-should-be-compulsory-inschools-20161122-gsvf6k.html

Mashiyi, N. 2014. Tertiary educators' reflections on language practices that enhance student learning and promote multilingualism. In L. Hibbert \& C. Van der Walt (Eds.). Multilingual universities in South Africa: Reflecting society in higher education (pp.145-163). https://doi. org/10.21832/9781783091669-011

Mdube, P. 2018. Decolonising education: Lessons from the Afrikaans language. Available at https://city-press.news24.com/News/decolonising-education-lessons-from-the-afrikaanslanguage-20180517

Merrington, Z. 2016. Mandarin has been introduced in 43 SA schools in 2016. Available at http://www.sabc.co.za/news/a/6180f1804d0b908490a3f293fd523eaa/ Mandarin-has-been-introduced-in-43-SA-schools-in-2016-20160607

Mheta, G., Lungu, B.N. \& Govender, T. 2018. Decolonisation of the curriculum: A case study of the Durban University of Technology in South Africa. South African Journal of Education, 38(4), 1-7. https://doi.org/10.15700/saje.v38n4a1635 
Modipane, M. \& Themane, M. 2014. Teachers' social capital as a resource for curriculum development: lessons learnt in the implementation of a child-friendly schools programme. South African Journal of Education, 34(4), 1-8. https://doi.org/10.15700/201412052105

Ndimande-Hlongwa, N. \& Ndebele, H. 2017. Embracing African languages as indispensable resources through the promotion of multilingualism. Per Linguam, 33(1), 67-82 https://doi. org/10.5785/33-1-692

Nel, N. 2016. Teaching and learning of Mandarin as a foreign language in South African schools. Perspectives in Education, 34(2), 43-56. DOI: https://doi.org/10.18820/2519593X/pie.v34i2.4

Neuman, W.L. 2014. Social research methods: Qualitative and quantitative approaches (7th ed). United States: Pearson.

News24. 2015. Mandarin to be introduced in SA schools. Available at www.news24.com/ SouthAfrica/.../Mandarin-to-be-introduced-in-SA-schools-201508

Ngcobo, S. 2013. Educators' attitudes towards the role of isiZulu in education: additive rather than exclusive. Southern African Linguistics and Applied Language Studies, 31(2), 185-205. https://doi.org/10.2989/16073614.2013.815838

Nkosi, B. 2015. Like it or not, SA schools set to teach Mandarin. Available at https://mg.co.za/ article/2015-08-12-like-it-or-not-sa-schools-set-to-teach-mandarin

Oroujlou, N. \& Vahedi, M. 2011. Motivation, attitude, and language learning. Procedia -Social and Behavioural Sciences, 29, 994-1000. https://doi.org/10.1016/j.sbspro.2011.11.333

Paton, G. 2014. Mandarin on the school curriculum under languages shake-up. Available at http://www.telegraph.co.uk/education/educationnews/10878445/Mandarin-on-the-schoolcurriculum-under-languages-shake-up.htm

Sakuragi, T. 2006. The relationship between attitudes toward language study and crosscultural attitudes. International Journal of Intercultural Relations, 30, 19-31. https://doi. org/10.1016/j.ijintrel.2005.05.017

Samuel, M. 2008. Accountability to whom? For what? Teacher identity and the Force Field Model of teacher development. Perspectives in Education, 26(2), 3-16.

Sarnoff, I. 1970. Social attitudes and the resolution of motivational conflict. In M. Jahoda \& N. Warren (Eds.). Attitudes. Harmondsworth: Penguin.

Sebolai, M. 2017. Effects of using an indigenous language in an English-medium university: Students' voices. In M. Ralarala, K. Barris, E. Ivala \& S. Siyepu (Eds.). African language and language practice in the 21st century (pp. 93-114). Cape Town: CASAS.

Tan, C.S.P. 2017. Teacher beliefs on I1 use in multilingual classrooms: A New Zealand university language centre. New Zealand Studies in Applied Linguistics, 23 (1), 17-32.

Teagle, A. \& Chiu, C. 2016. Op-Ed: Why introducing Mandarin in SA schools is not a good idea. Available at https://www.dailymaverick.co.za/article/2016-03-10-op-ed-why-introducingmandarin-in-sa-schools-is-not-a-good-idea/\#.WS_fpeuGPIU

Teddlie, C. \& Yu, F. 2007. Mixed methods sampling typology with examples. Journal of Mixed Methods Research, 1(1), 77-100. https://doi.org/10.1177/1558689806292430

Wang, D. 2013. English in the Chinese foreign language classroom. Switzerland: Peter Lang Ag. https://doi.org/10.3726/978-3-0351-0656-5 
Wessels, S., Trainin, G., Reeves, J., Catalano, T. \& Deng, Q. 2017. Pre-service teachers' confidence and attitudes toward teaching English learners. Teacher Education and Practice, 30(3), 443-461.

Writer, S. 2016. South Africa has only one qualified Mandarin teacher. News report, 21 April 2016. Available at https://businesstech.co.za/news/government/121201/ south-africa-has-only-one-qualified-mandarin-teacher/

Writer, S. 2019. Minister wants to "decolonise" education in South Africa. Available at https://businesstech.co.za/news/lifestyle/294654/ minister-wants-to-decolonise-education-in-south-africa/ 